\title{
Decision Support System for the Selection of Courses in the Higher Education using the Method of Elimination Et Choix Tranduit La Realite
}

\author{
Made Sudarma1, Anak Agung Kompiang Oka Sudana ${ }^{2}$, Irwansyah Cahya ${ }^{3}$ \\ ${ }^{1,3}$ Departement of Electrical Engineering,Computer System and Informatics, Udayana University, Indonesia \\ ${ }^{2}$ Departement of Information Technology, Udayana University, Indonesia
}

\author{
Article Info \\ Article history: \\ Received Oct 5, 2014 \\ Revised Dec 9, 2014 \\ Accepted Jan 5, 2015 \\ Keyword: \\ Courses \\ Decision Support System \\ ELECTRE Method \\ Web-based Application
}

\section{Corresponding Author:}

Made Sudarma

Departement of Electrical and Computer System Engineering,

Engineering Faculty, Udayana University,

Jimbaran Campus, Kuta 80361, Bali, Indonesia.

Email: msudarma@unud.ac.id, Telp./Fax. : +62361703315

\begin{abstract}
Each year thousands of prospective students attend new student enrollment in universities, which each prospective student have determined the courses that wish to be studied in college. Most of prospective student choose the courses only based on the number of enthusiasts and wishes of parents, and are not based on their academic ability. The impact of this phenomenon is that many of the prospective students chosen to switch courses and not a few of them have been punished dropout. This problem can be solved through the creation of decision support system that has an ability to suggest suitable courses to be selected by the prospective student based on their academic ability. This decision support system solved the problem using the method of elimination et choix tranduit la realite which is presented in web-based application to raise the accessibility by the prospective student.
\end{abstract}

Copyright (c) 2015 Institute of Advanced Engineering and Science. All rights reserved.

\section{INTRODUCTION}

The election of courses at the college level is the most important stages for a prospective student, which all of them must determine the scientific field that wanted to be learned or the courses that correlates with the profession to be achieved. Every year thousands of prospective student attend new student enrollment in universities, which each of prospective student have determined the courses that wish to be studied in college. However most of prospective student choose the courses only based on the number of enthusiasts and wishes of parents, and are not based on their own academic ability. The impact of this phenomenon is that many of the prospective students chosen to switch courses and not a few of them have been punished dropout. This problem can be solved through the creation of decision support system that has an ability to suggest suitable courses to be selected by the prospective student based on their academic ability.

Decision support system is an information system at the management level of an organization that combines data and sophisticated analytical models to support decision-making in condition of semistructured and unstructured. Decision support system can be interpreted asa model-based system consisting of procedures in processing the data and the results of the data processing is used to assist managers in making decisions. This model-based system should be simple, robust, easily controlled, adaptable, easily communicated and implicitly also means the system must be based computer so that system canfulfill its purpose [8]-[11]. 
The decision support system solved the courses election problem using the Method of Elimination Et Choix Tranduit La Realite or known as Method of ELECTRE. The basic concept of ELECTRE method is to handle the outranking relationship using pairwise comparisons between the one alternative with the other alternatives on each criterion separately [1], [2], [10]. The Outranking relations of $A_{i}$ and $A_{j}$ explained that when the-ith alternative didn't dominate the-jth alternative quantitatively, then the decision maker still can take the risk by choosing $A_{i}$ because $A_{i}$ is almost better than $A_{j}$. The alternative is said to be dominated if there is another alternative that outperform them in one or more of the same attributes and in the remaining attributes.

The Decision maker is asked to assign preference weights or important factor of criteria to reveal the relative importance of these criteria [4]. A series of assessment process carried out in a row against the outranking relations of alternatives. Concordance is defined as the set of some evidence to support the conclusion that $A_{k}$ outperform or dominate $A_{l}$. The set of Discordance is defined as the amount of evidence to support the conclusion that $A_{k}$ is worse than $A_{l}$ [5], [7]. This method has a clearer view about the alternative is to eliminate alternatives that are less favorable, when facing multiple criteria with a number of alternatives in the case of decision making [3].

\section{RESEARCH METHOD}

This decision support system is deliberately designed to be able to provide a solution in determining the choice of courses in Higher Education. This application designed using PHP programming language and HTML, which is integrated with several other programming languages such as JavaScript, Jquery and CSS.

\subsection{System Concept}

The use of this decision support system for the selection of courses begins with the login process. Prospective student who successfully perform the login process can start the decision making of the selection of courses, by providing input data in the form of academic ability and economic ability of the prospective student itself. The academic ability is comprised of the value of student report cards from grade 1 in 1 st semester to grade 3 in 2nd semester, when the prospective student were at high school level [6].

The input data is converted into a weight value in accordance with the system provisions and put in the input database, complete with id_user belongs users who have given the input data. The weight value of input data that already exist in the input database passed to the process of variable initialization simultaneously with the data of alternative weight taken from the courses database. All data that has been initialized is forwarded to the calculation process of decision-making using the ELECTRE method [1]. The result of the calculation process of decision-making is a suggestion in the form of coursesthat suitable to be selected by the user, which has been sorted by the system based on the acquisition of the dominance value of each courses [9].

\subsection{Research Phases}

This research was conducted through several stages, as follows:

1. Determination of problems or cases that examined in this study and limitations of the problem itself.

2. The collection of data which is related to the issues. The data collection was done by means of a literature study.

3. Designing the system in accordance with the problems studied and the data obtained, as well as implement the ELECTRE method to the system are made.

4. Connecting the interface of system with a database that has been created.

5. Conduct testing to the system that has been designed and created.

6. Performing an analysis on the results of the testing system.

7. Making conclusions.

8. Preparation of reports based on the stages of the research that has been done.

\section{RESULTS AND ANALYSIS}

The purpose of tests performed on applications of decision support system for the selection of courses is to determine the effectiveness and performance of application that have been created. The test will provide a conclusion on how effective the method could solve the problems and how well the performance implemented. 


\subsection{Test the Accuracy of the Calculation Results} follows.

Testing the accuracy of the calculation can be done through the completion of a case, which is as

The prospective student namely "user" making a selection of courses using this decision support system application, where the user input (value of report cards) are as follows.

1. Average value of Indonesia Language: 80

2. Average value of English: 90

3. Average value of mathematics: 70

4. Average value of Indonesian Literature: 90

5. Average value of Foreign Language: 70

6. Average value of Anthropology: 70

7. Average value of Computer Science: 75

8. Economic capacity per 1 semester: IDR 3.000.000,00

Completion of the above cases using manual calculation of ELECTRE method is as follows.

Alternative matrix (Matrix $X$ ) is:

Table 1. Alternative Matrix

\begin{tabular}{lllllllll}
\hline Alternative (Courses) & \multicolumn{7}{c}{ Weight value of each criterion } \\
& 1 & 2 & 3 & 4 & 5 & 6 & 7 & 8 \\
\hline Indonesian Literature & 5 & 2 & 2 & 5 & 3 & 2 & 3 & 1 \\
Ancient Javanese Literature & 4 & 2 & 2 & 3 & 3 & 3 & 2 & 1 \\
Literature of Bali & 4 & 2 & 2 & 4 & 3 & 4 & 3 & 1 \\
English Literature & 3 & 5 & 2 & 2 & 4 & 2 & 3 & 2 \\
Japanese Literature & 3 & 3 & 2 & 2 & 5 & 3 & 2 & 2 \\
Archeology & 2 & 3 & 4 & 2 & 3 & 5 & 4 & 1 \\
Cultural Anthropology & 2 & 3 & 2 & 2 & 4 & 5 & 3 & 1 \\
History & 3 & 3 & 2 & 2 & 2 & 4 & 3 & 1 \\
\hline
\end{tabular}

Where the representation of the weight value is:

$5=$ very good value

4= good value

$3=$ enough value

$2=$ bad value

$1=$ very bad value

The input data from user (value of report cards) converted into a preference weight based on the following conditions.

- $\quad$ If the value is in the range 85 to 100 , then the weight of preference is 5 .

- $\quad$ If the value is in the range 80 to 84 , then the weight of preference is 4 .

- $\quad$ If the value is in the range 75 to 79 , then the weight of preference is 3 .

- $\quad$ If the value is in the range 65 to 74 , then the weight of preference is 2 .

- $\quad$ If the value is in the range 10 to 64 , then the weight of preference is 1 .

The economic ability per 1 semester of user is also converted into a preference weight based on the following conditions.

- $\quad$ If the value is in the range Rp.4.200.000,00 to Rp.20.000.000,00 then the weight of preference is 5.

- $\quad$ If the value is in the range Rp.3.100.000,00 to Rp.4.100.000,00 then the weight of preference is 4.

- $\quad$ If the value is in the range Rp.2.600.000,00 to Rp.3.000.000,00 then the weight of preference is 3.

- $\quad$ If the value is in the range Rp.2.100.000,00 to Rp.2.500.000,00 then the weight of preference is 2 .

- $\quad$ If the value is in the range Rp.1.000.000,00 to Rp.2.000.000,00 then the weight of preference is 1.

Table 2. Preference weight

\begin{tabular}{ccccccccc}
\hline & \multicolumn{1}{c}{ Creference weights (interest rate of criterion) } \\
\cline { 2 - 10 } Input data from user & 1 & 2 & 3 & 4 & 5 & 6 & 7 & 8 \\
& 4 & 5 & 2 & 5 & 2 & 2 & 3 & 3 \\
\hline
\end{tabular}

Where the representation of the preference weight is:

$5=$ very important

Decision Support System for the Selection of Courses in the Higher Education using the ... (Made Sudarma) 
4= important

$3=$ quite important

$2=$ not important

$1=$ very unimportant

Phase 1. Determination of the normalized matrix.

$$
r_{i j}=\frac{x_{i j}}{\sqrt{\sum_{i=1}^{m} x_{i j}^{2}}} \text { untuk } i=1,2,3, \ldots, m \text { dan } j=1,2,3, \ldots, n
$$

The calculation is:

$$
\begin{aligned}
& \left|x_{1}\right|=\sqrt{5^{2}+4^{2}+4^{2}+3^{2}+3^{2}+2^{2}+2^{2}+3^{2}}=\sqrt{92}=9,5917 \\
& r_{11}=\frac{x_{11}}{\left|x_{1}\right|}=\frac{5}{9,5917}=0,5213 \\
& r_{21}=\frac{x_{21}}{\left|x_{1}\right|}=\frac{4}{9,5917}=0,4171 \\
& r_{31}=\frac{x_{31}}{\left|x_{1}\right|}=\frac{4}{9,5917}=0,4171 \\
& r_{41}=\frac{x_{41}}{\left|x_{1}\right|}=\frac{3}{9,5917}=0,3127 \\
& r_{51}=\frac{x_{51}}{\left|x_{1}\right|}=\frac{3}{9,5917}=0,3127 \\
& r_{61}=\frac{x_{61}}{\left|x_{1}\right|}=\frac{2}{9,5917}=0,2086 \\
& r_{71}=\frac{x_{71}}{\left|x_{1}\right|}=\frac{2}{9,5917}=0,2086 \\
& r_{81}=\frac{x_{81}}{\left|x_{1}\right|}=\frac{3}{9,5917}=0,3127
\end{aligned}
$$

\begin{tabular}{|c|c|c|c|c|c|c|}
\hline$[2,0852$ & 1,1705 & 0,603 & 2,9881 0,6092 & 0,3848 & 1,0836 & 0,8019 \\
\hline 1,6681 & 1,1705 & 0,603 & 1,7952 0,6092 & 0,5774 & 0,7221 & 0,8019 \\
\hline 1,6681 & 1,1704 & 0,603 & $2,39050,6092$ & 0,7698 & 1,0835 & 0,8018 \\
\hline 1,2511 & 2,926 & 0,603 & $1,19520,8123$ & 0,3849 & 1,0835 & 1,6035 \\
\hline$V=\mid 1,2511$ & 1,7556 & 0,603 & $1,19521,0153$ & 0,5774 & 0,7223 & 1,6035 \\
\hline 0,8341 & 1,7556 & 1,2061 & $1,19520,6092$ & 0,9623 & 1,4446 & 0,8018 \\
\hline 0,8341 & 1,7556 & 0,603 & $1,19520,8123$ & 0,9623 & 1,0835 & 0,8018 \\
\hline$\lfloor 1,2511$ & 1,7556 & 0,603 & $1,19520,4061$ & 0,7698 & 1,0835 & 0,8018 \\
\hline
\end{tabular}

Calculations performed in the same way so as to obtain the following results:

$R=\left[\begin{array}{lllllll}0,5213 & 0,2341 & 0,3015 & 0,59760,3046 & 0,1924 & 0,3612 & 0,2673 \\ 0,4171 & 0,2341 & 0,3015 & 0,35850,3046 & 0,2887 & 0,2407 & 0,2673 \\ 0,4171 & 0,2341 & 0,3015 & 0,47810,3046 & 0,3849 & 0,3612 & 0,2673 \\ 0,3127 & 0,5853 & 0,3015 & 0,23910,4062 & 0,1924 & 0,3612 & 0,5345 \\ 0,3127 & 0,3512 & 0,3015 & 0,23910,5077 & 0,2887 & 0,2407 & 0,5345 \\ 0,2086 & 0,3512 & 0,6031 & 0,23910,3046 & 0,4812 & 0,4815 & 0,2673 \\ 0,2086 & 0,3512 & 0,3015 & 0,23910,4062 & 0,4812 & 0,3612 & 0,2673 \\ 0,3127 & 0,3512 & 0,3015 & 0,23910,2031 & 0,3849 & 0,3612 & 0,2673\end{array}\right]$

Phase 2. Weighting the normalized matrix.

$V=R . W$

$$
\left[\begin{array}{ccc}
V_{11} V_{12} & \cdots & V_{1 n} \\
V_{21} V_{22} & \cdots & V_{2 n} \\
\vdots & \\
V_{m 1} V_{m 2} & \cdots & V_{m n}
\end{array}\right]=\left[\begin{array}{ccc}
w_{1} r_{11} w_{2} r_{12} & \cdots & w_{n} r_{1 n} \\
w_{1} r_{21} w_{2} r_{22} & \cdots & w_{n} r_{2 n} \\
\vdots & \\
w_{1} r_{m 1} w_{2} r_{m 2} & \cdots & w_{n} r_{m n}
\end{array}\right]
$$

Calculations performed in the same way so as to obtain the following results:

Phase 3. Determination of theconcordance set using the following conditions:

$$
C_{k l}=\left\{j, v_{k j} \geq v_{l j}\right\} \text { untuk } j=1,2,3, \ldots n
$$

The calculation is:

$C_{12}=\left\{j, v_{1 j} \geq v_{2 j}\right\} \quad \mathrm{j}=1,2, . .8$ then obtained $C_{12}=\{1,2,3,4,5,7,8\}$ means to meet the conditions in the 1st, 2nd, 3rd, 4th, 5th, 7th dan 8th comparisons.

$C_{13}=\left\{j, \quad v_{1 j} \geq v_{3 j}\right\} \mathrm{j}=1,2, . .8$ then obtained $C_{13}=\{1,2,3,4,5,7,8\}$

$C_{14}=\left\{j, v_{1 j} \geq v_{4 j}\right\} \mathrm{j}=1,2, . .8$ then obtained $C_{14}=\{1,3,4,6,7\}$

$C_{15}=\left\{j, v_{1 j} \geq v_{5 j}\right\} \mathrm{j}=1,2, . .8$ then obtained $C_{15}=\{1,3,4,7\}$

$C_{16}=\left\{j, v_{1 j} \geq v_{6 j}\right\} \mathrm{j}=1,2, . .8$ then obtained $C_{16}=\{1,4,5,8\}$ 
$C_{17}=\left\{j, v_{1 j} \geq v_{7 j}\right\} \mathrm{j}=1,2, . .8$ then obtained $C_{17}=\{1,3,4,7,8\}$

$C_{18}=\left\{j, v_{1 j} \geq v_{8 j}\right\} \mathrm{j}=1,2, . .8$ then obtained $C_{18}=\{1,3,4,5,7,8\}$

The calculation continued until all sets of concordance completely obtained.

Determination of the discordance set using the following conditions:

$$
D_{k l}=\left\{j, v_{k j}<v_{l j}\right\} \text { untuk } j=1,2,3, \ldots n
$$

The calculation is:

$D_{12}=\left\{j, v_{1 j}<v_{2 j}\right\} \quad \mathrm{j}=1,2, . .8$ then obtained $D_{12}=\{6\}$ means to meet the conditions in the 6th comparisons.

$D_{13}=\left\{j, v_{1 j}<v_{3 j}\right\} \mathrm{j}=1,2, . .8$ then obtained $D_{13}=\{6\}$

$D_{14}=\left\{j, v_{1 j}<v_{4 j}\right\} \mathrm{j}=1,2, . .8$ then obtained $D_{14}=\{2,5,8\}$

$D_{15}=\left\{j, \quad v_{1 j}<v_{5 j}\right\} \mathrm{j}=1,2, . .8$ then obtained $D_{15}=\{2,5,6,8\}$

$D_{16}=\left\{j, v_{1 j}<v_{6 j}\right\} \mathrm{j}=1,2, . .8$ then obtained $D_{16}=\{2,3,6,7\}$

$D_{17}=\left\{j, v_{1 j}<v_{7 j}\right\} \mathrm{j}=1,2, . .8$ then obtained $D_{17}=\{2,5,6\}$

$D_{18}=\left\{j, v_{1 j}<v_{8 j}\right\} \mathrm{j}=1,2, . .8$ then obtained $D_{18}=\{2,6\}$

The calculation continued until all sets of discordance completely obtained.

Phase 4. Calculation of matrix of concordance and discordance.

$$
c_{k l}=\sum_{j \in C_{k l}} w_{j}
$$

The calculation is:

$$
\begin{aligned}
& C_{12}=w_{1}+w_{2}+w_{3}+w_{4}+w_{5}+w_{7}+w_{8}=4+5+2+5+2+3+3=24 \\
& C_{13}=w_{1}+w_{2}+w_{3}+w_{4}+w_{5}+w_{7}+w_{8}=4+5+2+5+2+3+3=24 \\
& C_{14}=w_{1}+w_{3}+w_{4}+w_{6}+w_{7}=4+2+5+2+3=16 \\
& C_{15}=w_{1}+w_{3}+w_{4}+w_{7}=4+2+5+3=14 \\
& C_{16}=w_{1}+w_{4}+w_{5}+w_{8}=4+5+2+3=14 \\
& C_{17}=w_{1}+w_{3}+w_{4}+w_{7}+w_{8}=4+2+5+3+3=17 \\
& C_{18}=w_{1}+w_{3}+w_{4}+w_{5}+w_{7}+w_{8}=4+2+5+2+3+3=19
\end{aligned}
$$

Calculations performed in the same way so as to obtain the following results:

$C=\left[\begin{array}{ccccccc}0 & 24 & 24 & 1614 & 14 & 17 & 19 \\ 14 & 0 & 16 & 1316 & 14 & 14 & 16 \\ 17 & 26 & 0 & 1616 & 14 & 17 & 21 \\ 17 & 15 & 15 & 022 & 19 & 24 & 24 \\ 14 & 17 & 12 & 180 & 19 & 21 & 21 \\ 17 & 17 & 17 & 1217 & 0 & 24 & 22 \\ 17 & 17 & 17 & 1417 & 21 & 0 & 22 \\ 15 & 15 & 15 & 1621 & 17 & 22 & 0\end{array}\right]$

The matrix of discordance is calculated based on the set of discordance that obtained at phase 3 , as follows:

$$
d_{k l}=\sum_{j \in D_{k l}} w_{j}
$$

The calculation is:

$$
\begin{aligned}
& D_{12}=w_{6}=2 \\
& D_{13}=w_{6}=2 \\
& D_{14}=w_{2}+w_{5}+w_{8}=5+2+3=10 \\
& D_{15}=w_{2}+w_{5}+w_{6}+w_{8}=5+2+2+3=12 \\
& D_{16}=w_{2}+w_{3}+w_{6}+w_{7}=5+2+2+3=12 \\
& D_{17}=w_{2}+w_{5}+w_{6}=5+2+2=9 \\
& D_{18}=w_{2}+w_{6}=5+2=7
\end{aligned}
$$

Calculations performed in the same way so as to obtain the following results:

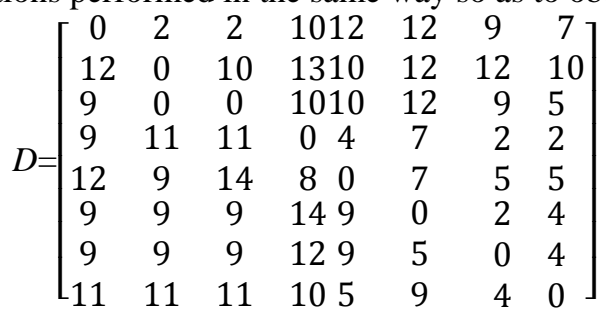


Phase 5. Determination of the dominance value of concordance and discordance.

Table 3. The dominance value of concordance

\begin{tabular}{lcc}
\hline Courses (alternative) & $\begin{array}{c}\text { Calculation of the dominance value } \\
\text { of concordance }\end{array}$ & $\begin{array}{c}\text { The dominance value of } \\
\text { concordance }\end{array}$ \\
\hline Indonesian Literature & $0+24+24+16+14+14+17+19$ & 128 \\
Ancient Javanese Literature & $14+0+16+13+16+14+14+16$ & 103 \\
Literature of Bali & $17+26+0+16+16+14+17+21$ & 127 \\
English Literature & $17+15+15+0+22+19+24+24$ & 136 \\
Japanese Literature & $14+17+12+18+0+19+21+21$ & 122 \\
Archeology & $17+17+17+12+17+0+24+22$ & 126 \\
Cultural Anthropology & $17+17+17+14+17+21+0+22$ & 125 \\
History & $15+15+15+16+21+17+22+0$ & 121 \\
\hline
\end{tabular}

The calculation of the dominance value of discordance is as follows:

Table 4. The dominance value of discordance

\begin{tabular}{lrc}
\hline Courses (alternative) & $\begin{array}{c}\text { Calculation of the dominance value } \\
\text { of discordance }\end{array}$ & $\begin{array}{c}\text { The dominance value } \\
\text { of discordance }\end{array}$ \\
\hline Indonesian Literature & $0+2+2+10+12+12+9+7$ & 54 \\
Ancient Javanese Literature & $12+0+10+13+10+12+12+10$ & 79 \\
Literature of Bali & $9+0+0+10+10+12+9+5$ & 55 \\
English Literature & $9+11+11+0+4+7+2+2$ & 46 \\
Japanese Literature & $12+9+14+8+0+7+5+5$ & 60 \\
Archeology & $9+9+9+14+9+0+2+4$ & 56 \\
Cultural Anthropology & $9+9+9+12+9+5+0+4$ & 57 \\
History & $11+11+11+10+5+9+4+0$ & 61 \\
\hline
\end{tabular}

Phase 6. The final dominance is the result of a reduction in the dominance between the concordance and discordance value of an alternative.

Table 5. The result of the manual calculation

\begin{tabular}{lcc}
\hline Courses (alternative) & $\begin{array}{c}\text { The value of the final } \\
\text { dominance }\end{array}$ & $\begin{array}{c}\text { Ranked based on the value of the } \\
\text { final dominance }\end{array}$ \\
\hline Indonesian Literature & 74 & 2 \\
Ancient Javanese Literature & 24 & 8 \\
Literature of Bali & 72 & 3 \\
English Literature & 90 & 1 \\
Japanese Literature & 62 & 6 \\
Archeology & 70 & 4 \\
Cultural Anthropology & 68 & 5 \\
History & 60 & 7 \\
\hline
\end{tabular}

Table 6. Comparisons of the calculation results

\begin{tabular}{lccc}
\hline Courses (alternative) & $\begin{array}{c}\text { The value of the final } \\
\text { dominance (result of the manual } \\
\text { calculation) }\end{array}$ & $\begin{array}{c}\text { The value of the final } \\
\text { dominance (result of the } \\
\text { calculation of application) }\end{array}$ & $\begin{array}{c}\text { Ranked based on the } \\
\text { value of the final } \\
\text { dominance }\end{array}$ \\
\hline Indonesian Literature & 74 & 74 & 2 \\
Ancient Javanese Literature & 24 & 24 & 8 \\
Literature of Bali & 72 & 72 & 3 \\
English Literature & 90 & 90 & 1 \\
Japanese Literature & 62 & 62 & 6 \\
Archeology & 70 & 70 & 4 \\
Cultural Anthropology & 68 & 68 & 5 \\
History & 60 & 60 & 7 \\
\hline
\end{tabular}

The comparisons resultat Table 6 shows the calculation process of decision making using applications capable of generating output that has a very good level of accuracy and in accordance with the rules of calculation of ELECTRE method. 


\section{CONCLUSION}

The use of ELECTRE method in the application of decision support system for the selection of courses in college is very effective and relevant. This is because the ELECTRE method is able to process the input data by using a relatively short calculation and is able to generate output data as expected, taking into account the advantages and drawbacks of each alternative (courses). Output data resulting from calculations using ELECTRE method is also presented in the form of rating, making it easier for users to analyze the system output and determine the courses that suitable to be chosen.

\section{ACKNOWLEDGEMENTS}

I would like to express my very great appreciation to goes to colleague who has made valuable contributions in this study and their critical comments on this manuscript.

\section{REFERENCES}

[1] Chen, C.H. and Huang, W.C., "Using The ELECTRE II Method to Apply and Analyze The Differentiation Theory”, Proceeding of The Eastern Asia Society For Transportation Studies,vol. 5, pp. 2237-2249, 2005.

[2] Ermatita, et al., "ELECTRE Methods in Solving Group Decision Support System Bioinformatics On Gene Mutation Detection Simulation”, International Journal of Computer Science \& Information Technology (IJCSIT), vol. 3 no. 1, pp. 40-52, 2011.

[3] Figueira, J.R.,et al.,"An Overview of ELECTRE Methods and Their Recent Extensions”, Journal of Multi-Criteria Decision Analysis, vol. 20, pp. 61-85, 2013.

[4] Jihong, P., et al., "ELECTRE I Decision Model of Reliability Design Scheme For Computer Numerical Control Machine”, Journal Of Software, vol. 6 no. 5, pp. 894-900, 2011.

[5] Milani, A.S.,et al., "Using Different ELECTRE Methods in Strategic Planning in The Presence of Human Behavioral Resistance”, Journal of Applied Mathematics and Decision Sciences, vol. 206, pp. 1-19, 2006.

[6] Paul, L.D., et al., "Examining The Implications of Process and Choice For Strategic Decision Making Effectiveness”, International Journal of Decision Support System Technology, vol. 2 no. 3, pp. 1-15, 2010.

[7] Prasenjit, C., et al., "A Comprehensive Solution To Automated Inspection Device Selection Problems Using ELECTRE Methods”, International Journal of Technology, vol. 2, pp. 193-208, 2014.

[8] Raul, V., “A Risk Management Decision Support System For The Real Estate Industry”, International Journal of Information and Communication Technology Research, vol. 1 no. 3, pp. 139-147, 2011.

[9] Rosmayati, M., et al., "Decision Support Systems (DSS) in Construction Tendering Processes”, IJCSI International Journal of Computer Science Issues, vol. 7 no. 1, pp. 35-45, 2010.

[10] Tooba, A., "Formulating Forest Management Strategies Using ELECTRE Method (Case Study: District 2 Nav, Asalem, Guilan, Iran)”, World Applied Programming, vol. 3, pp. 522-528, 2013.

[11] Whetyningtyas, A., "Peranan Decision Support Systems (DSS) Bagi Manajemen Selaku Decision Maker", Journal. Fakultas Ekonomi Universitas Muria Kudus. vol.5 no.1, pp. 104-106, 2011. 